\title{
COMPARISON OF ULTRASONIC TECHNIQUES FOR THE DETECTION OF PREGNANCY IN EWES
}

\author{
IVAN L. LINDAHL \\ Agricultural Research Center, U.S. Department of Agriculture, \\ Beltsville, Maryland
}

(Received 13th Fune 1968, revised 30th September 1968)

\begin{abstract}
Summary. Ultrasonic techniques can be used with great accuracy for the detection of pregnancy in ewes which are at least 65 days pregnant. The Doppler technique resulted in a greater accuracy in the detection of pregnancy than did the Amplitude-depth ultrasound technique. These two techniques may be used simultaneously to detect reproductive tract abnormalities. Prediction of multiple pregnancies was not successful with either technique. Pregnancy was detected as early as 115 days before lambing with both techniques.
\end{abstract}

Amplitude-depth (A-scope) ultrasound has been used for the detection of pregnancy in ewes (Lindahl, 1966). Preliminary reports also indicate that the Doppler principle might be useful for detecting foetal life in ewes (Fraser \& Robertson, 1967; Shelton, 1968; Hulet, personal communication).

The A-scope and Doppler techniques were compared under field conditions from 13th November 1967 to 7th January 1968. Six hundred and sixty-two ewes of different ages, sizes and breeds were examined by both techniques (Groups I, II, III and IV). Before the two techniques were compared, sixty-six ewes were examined using only the Doppler principle (Group Ia, Table 1). Thirty-eight ewes were judged to be pregnant and were not subjected to further examination; the other twenty-eight ewes were included in Group I. All ewes not diagnosed as pregnant by both techniques in Groups I, II, III and IV were re-examined at a later date. In a different trial, 120 examinations, using both techniques, were made on ewes constantly exposed to rams except during late gestation and for approximately a week after lambing. Examinations of these ewes were made on 10th October, 11 th November and 7th December 1967.

At examination, the wool was clipped in front of the udder with a small animal clipper fitted with a surgical blade. This area and the areas between the hind legs and abdomen were cleaned with soapy water. A water soluble lubricant or gel (K-Y Sterile Lubricant, Johnson and Johnson, New Brunswick, New Jersey) was used as a contact medium for ultrasonic transmission in both techniques. Except for the contact medium, the A-scope technique and 


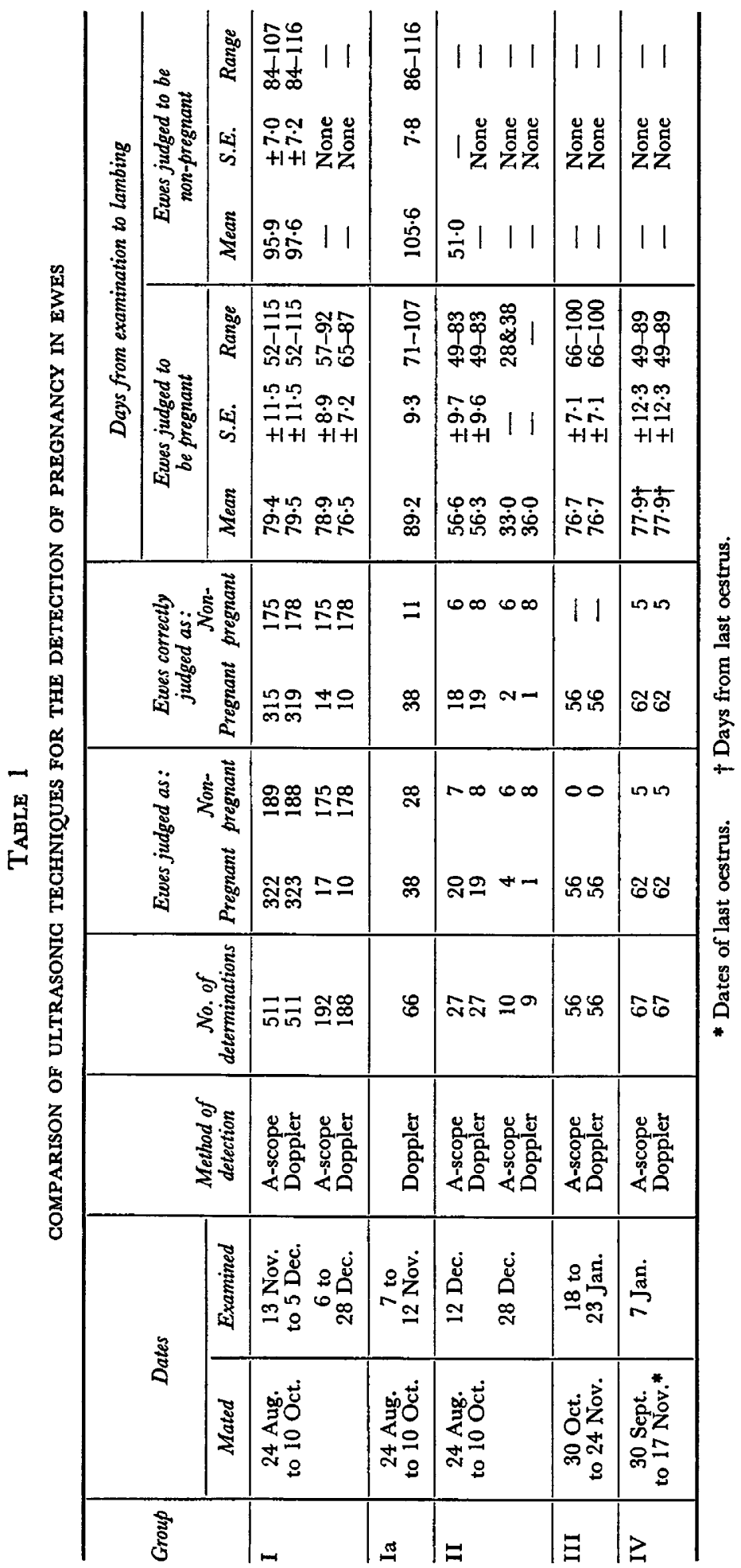


instrument were the same as described previously (Lindahl, 1966). The Doppler instrument used a frequency of $5 \mathrm{Mcyc} / \mathrm{sec}$ and a transducer with a diameter of $3.5 \mathrm{~cm}$ (Ames Ultradop, Ames Company, Division Miles Laboratory, Elkhart, Indiana). All ewes were examined in the standing position.

Ewes could be examined with the A-scope at the rate of one every minute. With the Doppler technique a systematic search of the posterior abdomen was made by slowly moving the transducer backwards and forwards and from the right to the left side. A ewe was diagnosed as non-pregnant if either foetal heart beat, foetal blood flow or foetal movement was not detected within $5 \mathrm{~min}$. Foetal heart beat or pulse was detected with the Doppler instrument within an average of $48 \mathrm{sec}$ ( $2 \mathrm{sec}$ to $5 \mathrm{~min}$ ) during determinations on ninety pregnant ewes at different stages of pregnancy. Due to the longer search period used in non-pregnant ewes, diagnosis by the Doppler technique took approximately twice as long as by the A-scope technique.

Data regarding dates of mating and examination, and the results of pregnancy detection in all ewes, except those with the rams continuously, are given in Table I. The results of Groups I, II and III were confirmed by lambing records and those in Group IV by laparotomy.

None of the ewes judged to be non-pregnant at a second examination lambed in any of the four Groups. In Group I, four ewes judged to be pregnant by both techniques were not detected as having lambed or aborted; however, it is possible that abortion was not detected. Three ewes in Group I and two ewes in Group II were diagnosed as pregnant by the A-scope technique, but as non-pregnant by the Doppler technique. These five ewes, which were the only ewes giving conflicting results, were killed and examined. One ewe had a large fibromatous uterus, one had a severe infection of the uterine tract and three ewes had swollen uterine horns filled with thick mucous. Since positive diagnosis of pregnancy by the A-scope technique depends on obtaining echoes from the developing pregnant uterus, conditions resulting in enlarged uterine horns filled with fluid, mucous or abnormal tissue can result in false diagnosis of pregnancy. By contrast, foetal life must be present for a positive diagnosis of pregnancy by the Doppler technique. Simultaneous use of the two techniques may be useful for detection of reproductive tract abnormalities.

Of fifty-nine ewes constantly exposed to rams, except during late pregnancy, fifty-eight were correctly diagnosed as pregnant by the Doppler technique and fifty-seven by the A-scope technique. All the pregnant ewes were successfully detected by one or the other technique. One ewe aborted and the remainder diagnosed as pregnant by the Doppler technique lambed $75 \cdot 1 \pm 14 \cdot 6$ days after examination, while those diagnosed as pregnant by the A-scope technique lambed $75 \cdot 9 \pm 15 \cdot 0$ days after examination. Although the mean number of days from the detection of pregnancy until lambing was longer by 8.7 and 9.5 days, respectively, for ewes with multiple births than for those with singles, the results were not statistically different. Analysis of all the data in these experiments also revealed that the percentage of multiple births from ewes correctly judged to be pregnant 90 to 115 days before lambing was not different from the percentage of all ewes giving birth to more than one lamb. Although these experiments were not designed to determine the earliest date 
at which pregnancy could be accurately detected by ultrasonic techniques, it is evident that pregnancy was detected with great accuracy in ewes 65 or more days after mating. It also appears that the earliest time at which pregnancy could be detected by using external transducers with either the Doppler or A-scope technique was between 40 and 50 days after mating.

\section{REFERENCES}

Fraser, A. F. \& Robertson, J. G. (1967) The detection of foetal life in ewes and sows. Vet. Rec. 80, 528.

LiNDAHL, I. L. (1966) Detection of pregnancy in sheep by means of ultrasound. Nature, Lond. 212, 642.

Shelton, M. (1968) A method of pregnancy diagnosis in sheep. Rep. Tex. agric. Exp. Stn., PR 2517. 